\title{
Quality of life of patients with inflammatory bowel disease
}

\author{
Qualidade de vida da pessoa com doença inflamatória intestinal \\ Calidad de vida de la persona con enfermedad inflamatoria intestinal \\ Lúcia Maria Torres dos Santos Gil*iD; Isabel Maria Ribeiro Fernandes** (D)
}

\begin{abstract}
Background: Inflammatory bowel disease (IBD) usually affects young adults and has a chronic, relapsing-remitting course, with an impact on patients' quality of life, namely on their health, education, profession, and social and family life.

Objectives: To assess the levels of quality of life of patients with IBD and identify the quality of life-related factors. Methodology: A descriptive-correlational, cross-sectional study was conducted with a quantitative approach. The consecutive and convenience sample was composed of 38 participants. An instrument that consisted of sociodemographic variables, clinical variables, and behavioral habits, as well as the Inflammatory Bowel Disease Questionnaire-Revised (IBDQ-R) was applied.

Results: A statistically significant association was found between quality of life, in the Social function dimension, and education level, hospital admissions, and smoking habits.

Conclusion: Patients with IBD perceived their quality of life as reasonable (45.80\%), with higher scores in the Systemic symptoms dimension (49.50\%) and lower scores in the Social function dimension (36.50\%).
\end{abstract}

Keywords: inflammatory bowel diseases; quality of life

\section{Resumo}

Enquadramento: A doença inflamatória intestinal (DII) afeta geralmente adultos jovens e tem um curso clínico crónico recidivante, com impacto na qualidade de vida, nomeadamente em aspetos relacionados com a saúde, educação, profissão, vida social e familiar.

Objetivos: Avaliar o nível de qualidade de vida das pessoas com DII e identificar os fatores relacionados com a qualidade de vida.

Metodologia: Trata-se de um estudo descritivo-correlacional, transversal e de tipo quantitativo. A amostra do estudo foi consecutiva e por conveniência, constituída por 38 participantes, tendo sido aplicado um questionário constituído por variáveis sociodemográficas, clínicas e hábitos comportamentais e pelo instrumento de avaliação Inflammatory Bowel Disease Questionnaire - Revised (IBDQ-R).

Resultados: Verifica-se relação estatisticamente significativa entre a qualidade de vida, na dimensão Aspetos sociais e o nível de escolaridade, a existência de internamentos e a existência de hábitos tabágicos.

Conclusáo: As pessoas com DII consideram ter uma perceção da qualidade de vida razoável $(45,80 \%)$, com valores superiores na dimensão Sintomas sistémicos $(49,50 \%)$ e inferiores na dimensão Aspetos sociais (36,50\%).

Palavras-chave: doenças inflamatórias intestinais; qualidade de vida

*MSc., Clinical Nurse Specialist in Community Nursing, Hospital Sousa Martins, 6300035, Guarda, Portugal [luciagil72@sapo.pt]. (D https://orcid.org/0000-0002-1890-2411. Contribution to the article: literature search; data collection; statistical treatment and evaluation; data analysis and discussion; article writing.

**Ph.D., Adjunct Professor, Polvtechnic Institute of Guarda. Health Sciences Research Unit: Nursing, 3046-851, Coimbra, Portugal [isabelfernandes@ipg.pt]. (D https://orcid.org/0000-0001-7478-9567. Contribution to the article: research guidance; methodological design; article writing. Address for correspondence: Avenida Cidade Safed, Lote 4, $2^{\circ}$ esq, 6300-537, Guarda, Portugal.

Revista de Enfermagem Referência

\section{Resumen}

Marco contextual: La enfermedad inflamatoria del intestino (EII) afecta generalmente a adultos jóvenes y tiene un curso clínico crónico y recidivante, con un impacto en la calidad de vida, en particular a los aspectos relacionados con la salud, la educación, la profesión, la vida social y familiar.

Objetivos: Evaluar el nivel de calidad de vida de las personas con EII y identificar los factores relacionados con la calidad de vida.

Metodología: Estudio descriptivo, correlacional, transversal, cuantitativo. La muestra del estudio constó de 38 participantes y consistió en la aplicación de cuestionarios compuestos por variables sociodemográficas, clínicas y de comportamiento y el Inflammatory Bowel Disease Questionnaire - Revised (IBDQ-R).

Resultados: existe una relación estadísticamente significativa entre la calidad de vida en la dimensión Aspectos sociales y el nivel de escolaridad; la existencia de hospitalizaciones y la existencia de hábitos de fumar.

Conclusión: Las personas con EII consideran tener un razonable nivel de la calidad de vida (45,80\%), con valores más altos en la dimensión de Síntomas sistémicos (49,50\%) y más bajos en la dimensión de Aspectos sociales $(36,50 \%)$.

Palabras clave: enfermedades inflamatorias del intestino; calidad de vida 


\section{Introduction}

Inflammatory bowel disease (IBD) is a chronic disease that is characterized by chronic intestinal inflammation and consists of two main forms: Crohn's disease (CD) and ulcerative colitis (UC). CD is characterized by a discontinuous, transmural inflammation of any part of the gastrointestinal tract. UC is the most common type, and, unlike $\mathrm{CD}$, is restricted to the mucosa, thus these patients are less susceptible to complications and many of them have moderate disease activity (Smeltzer, Bare, Hinkle, \& Cheever, 2011).

They correspond to a group of autoimmune diseases that affect the intestinal mucosa, involve frequent relapses, and are very debilitating. IBD is associated with a variety of intestinal, extraintestinal, and systemic manifestations, requiring frequent hospitalizations and long-term therapy, which have a direct impact on the physical, psychological, and social well-being of patients (Magalhães et al., 2015; Vasconcelos, Rocha, Souza, \& Amaral, 2018).

In Europe, the incidence and prevalence of IBD have increased and it is estimated to affect approximately $0.30 \%$ of the population, presenting a wide geographic variation. In Portugal, the prevalence of IBD has been steadily increasing and is estimated to be $150 / 100,000$ inhabitants, with a tendency to increase, which will have direct consequences on these patients' well-being and quality of life (QoL; Rede Nacional de Especialidade Hospitalar e de Referenciação, 2016).

The concept of QoL is marked by the subjectivity that involves the entire human condition, either in terms of the physical dimension or the psychological, social, cultural, and spiritual dimensions. This holistic view of the human being is the basic foundation for the provision of high-quality, comprehensive nursing care to an individual who is more vulnerable and lacks support and help to meet their needs, in both community and hospital settings.

This topic is particularly interesting for the development of research studies on the impact of a chronic disease on patients' perceived well-being and QoL. This study aimed to assess the QoL of patients with IBD and identify the factors influencing their QoL. The results will lead to changes in the behaviors of patients and healthcare professionals, as well as provide data and contribute to the development of nursing.

\section{Background}

IBD represents a group of chronic idiopathic inflammatory bowel conditions which result from persistent and inappropriate activation of the mucosal immune system, thus it is considered an autoimmune disease in its various manifestations (Neves, 2015).

The two main disease categories of IBD are $\mathrm{CD}$ and UC, which have both overlapping and distinct clinical and pathological features, allowing for a differential diagnosis (World Gastroenterology Organisation Practice Guidelines, 2015).

The symptoms of patients with IBD can lead to major changes in their well-being and in the several dimensions that characterize human life. Symptoms include fatigue, pain, and bowel changes that may lead to social isolation because they interfere with the social, professional, and affective dimensions. It usually affects young adults, and has an impact on their health-related QoL, particularly in aspects related to education, profession, social and family life.

Treatment can be pharmacological and/or surgical, depending on the type of disease and its severity. The purpose is to eliminate the inflammatory crises, suppress the inappropriate immune responses, and allow the bowel time to rest and heal. In addition, it also aims to relieve symptoms, reduce the need for surgery, prevent future relapses, suspend the use of corticosteroids, and reduce the number of hospital admissions, contributing to improve patients' QoL (Matos \& Figueiredo, 2013; Smeltzer et al., 2011).

According to the epidemiological studies carried out in recent decades, the incidence of IBD in the world population has been increasing, and it may be associated with lifestyle changes (diet, smoking habits, sedentary lifestyle, stress) and the possibility for earlier diagnosis due to improved complementary diagnostic tests.

In Portugal, this disease affects approximately 15,000 to 20,000 inhabitants, mostly young and active people. Some cases can be treated in outpatient settings, but more severe cases may require more specific treatment and hospitalization. With the purpose of assessing the clinical 
and economic impact on the organization and performance of gastroenterology services, a survey on digestive disorders was conducted by the United European Gastroenterology in the spring of 2013. This survey revealed an increase in the incidence of most gastrointestinal disorders across Europe, particularly IBD, with implications for the future provision of healthcare. IBD, among other gastrointestinal disorders, has a major impact on QoL, work productivity, and absenteeism (Rede Nacional de Especialidade Hospitalar e de Referenciação, 2016).

IBD has a significant impact on QoL, with the levels varying depending on whether the disease is active or in remission. In the most active phase, the effects of bowel symptoms are visible on people's lives and, consequently, on their ability to perform both their activities of daily living and their leisure and professional activities (Trindade, Ferreira, \& Gouveia, 2016). Patients have to significantly change their life projects in the short, medium and long term, as well as change their routines, habits, and behaviors, and embrace new ways of thinking and doing things.

There has been a major investment in the development of techniques and strategies for coping with IBD so as to improve the patients' well-being, adaptation, and acceptance of the disease (Trindade et al., 2016). It is important to understand the impact of the disease on the daily life of patients/families so as to help them throughout this disease process, increasing their well-being and satisfaction and, consequently, their QoL.

The multidisciplinary team who cares for people with chronic diseases must consider not only the biological and physical aspects but also the psychosocial impact of the disease. Patients with IBD are part of a group of people with specific needs who require monitoring, thus effective care should be provided and intervention programs and projects should be developed with a view to empowering them at an individual, family, and community level.

\section{Research question/Hypotheses}

What are the levels of QoL of people with IBD? Hypothesis 1: There is an association between the QoL of people with IBD and the socio- demographic variables, Hypothesis 2 - There is an association between the QoL of people with IBD and the behavioral habits; Hypothesis 3 - There is an association between the QoL of people with IBD and the clinical variables.

\section{Methodology}

This descriptive-correlational, cross-sectional study was conducted with a quantitative approach.

A set of variables were assessed: the dependent variable was the QoL of people with IBD and the independent variables included the sociodemographic characteristics (age, gender, marital status, education level, and professional situation); the behavioral habits (smoking and alcohol), and the clinical variables (confirmation of diagnosis, hospital admissions, and time of diagnosis).

The following inclusion criteria were applied: individuals with IBD attending the outpatient consultation of a local health unit in the Center region of Portugal, aged 18 to 65 years, knowing how to read and write in Portuguese, with cognitive abilities to fill out the questionnaire, and accepting to participate in the study on a voluntary basis.

Data were collected through the application of an instrument composed of two parts. The first part was composed of a set of questions on three dimensions: Sociodemographic, Behavioral, and Clinical. The second part was composed of the Inflammatory Bowel Disease Questionnaire-Revised (IBDQ-R), which was translated and validated for the Portuguese population by Veríssimo (2008). This questionnaire assessed different aspects of QoL, which are grouped in four dimensions: Bowel Symptoms (10 items); Systemic Symptoms (5 items), Emotional Function (12 items), and Social Function (5 items), addressing issues related to patients' symptoms, how they had been feeling and their state of mind in the last two weeks, thus contributing to a better understanding of the patients' adaptation to their condition (Veríssimo, 2008). This instrument was self-completed by the participants who were able to fill it out and completed with the help of the researcher in the case of older participants. The consecutive sample chosen by convenience was composed 
of 38 individuals who attended the outpatient consultation from January to September 2017. The number of participants was determined using Epi-Info, version 7, based on the target population, corresponding to a minimum of 33 participants.

Permission to conduct this study was asked to and granted by the Ethics Committee of the Local Health Unit, with registration number 11129 of 20 December 2016. A formal request in writing was also sent to the author of the questionnaire used in this study and an informed consent form was elaborated and delivered to the participants.

For the inferential analysis, non-parametric tests were used (Mann-Whitney $U$; Kruskal-Wallis $K$; and Spearman's correlation coefficient) due to the small sample size, namely when divided into subgroups to test for the hypotheses. The critical level of significance of the results of the hypotheses testing was set at 0.05 , rejecting the null hypothesis when the probability of making a type I error was lower than that value $(p<$ $0.05)$. Data were analyzed using IBM SPSS Statistics, version 20.0.

Internal consistency was analyzed using
Cronbach's alpha coefficient. The values obtained ranged from 0.72 to 0.89 for the different dimensions of QoL and 0.93 for the total IBDQ-R, which is similar to those obtained by Veríssimo (2008), with values ranging from 0.77 to 0.87 for the different dimensions and 0.92 for the total IBDQ-R.

\section{Results}

The sample was composed of 19 women and 19 men. Their main sociodemographic variables are described in Table 1 . The mean age was 43.20 years; $28.90 \%$ of them had the $12^{\text {th }}$ grade and higher education; most of them were married $(65.80 \%)$ and employed $(57.80 \%)$. CD was the most common condition (19;50.0\%), followed by UC $(10 ; 26.30 \%)$ and undetermined IBD $(9 ; 23.70 \%)$. The majority of people reported never having smoked $(65.80 \%)$ and not drinking alcohol (71.10\%). Fifteen patients $(39.50 \%)$ were hospitalized, mainly due to hemorrhage $(n=4)$ and exacerbation of the disease $(n=3)$. The time of diagnosis ranged from 1 to 29 years, with a mean of 8.80 years.

Table 1

Association between the dependent variable (QoL) and the independent variables

\begin{tabular}{|c|c|c|c|c|c|}
\hline \multicolumn{3}{|c|}{ Independent Variables } & \multirow{2}{*}{$\begin{array}{l}N \\
19\end{array}$} & \multirow{3}{*}{$\begin{array}{c}\boldsymbol{p} \\
\text { (IBDQ- } \\
\text { R Total) } \\
0.103\end{array}$} & \multirow{3}{*}{$\begin{array}{c}\text { Dimension with a } \\
\text { statistically } \\
\text { significant } \\
\text { association }\end{array}$} \\
\hline \multirow{8}{*}{ Sociodemographic } & \multirow{2}{*}{ Gender } & Female & & & \\
\hline & & Male & 19 & & \\
\hline & \multirow{2}{*}{ Marital status } & Married & 25 & \multirow{2}{*}{0.210} & \\
\hline & & Unmarried & 13 & & \\
\hline & \multirow{2}{*}{ Education level } & $<12^{\text {th }}$ grade & 16 & \multirow{2}{*}{0.711} & \multirow{2}{*}{$\begin{array}{c}\text { Social aspects } \\
\qquad \begin{array}{c}p .020\end{array}\end{array}$} \\
\hline & & $>12^{\text {th }}$ grade & 22 & & \\
\hline & \multirow{2}{*}{$\begin{array}{l}\text { Professional situ- } \\
\text { ation }\end{array}$} & Employed & 22 & \multirow{2}{*}{0.651} & \\
\hline & & Unemployed & 16 & & \\
\hline \multirow{4}{*}{ Behavioral } & \multirow[t]{2}{*}{ Smoking habits } & $\begin{array}{l}\text { Smokes or has } \\
\text { smoked }\end{array}$ & 13 & \multirow[t]{2}{*}{0.030} & \multirow{2}{*}{$\begin{array}{c}\text { Social aspects } \\
p=\mathbf{0 . 0 3 0}\end{array}$} \\
\hline & & Has never smoked & 25 & & \\
\hline & \multirow{2}{*}{ Drinking habits } & None & 27 & \multirow{2}{*}{0.161} & \\
\hline & & Light or moderate & 11 & & \\
\hline
\end{tabular}




\begin{tabular}{|c|c|c|c|c|c|}
\hline \multirow{6}{*}{ Clinical } & \multirow{3}{*}{ Diseases } & Crohn's disease & 19 & \multirow{3}{*}{0.166} & \\
\hline & & Ulcerative colitis & 10 & & \\
\hline & & $\begin{array}{l}\text { Undetermined } \\
\text { IBD }\end{array}$ & 9 & & \\
\hline & \multirow{2}{*}{$\begin{array}{l}\text { Hospital admis- } \\
\text { sion }\end{array}$} & No & 23 & \multirow{2}{*}{0.273} & Social aspects \\
\hline & & Yes & 15 & & $p=0.022$ \\
\hline & Years of diagnosis & & 38 & 0.890 & \\
\hline
\end{tabular}

Note. $p$ = significance test; IBD = Inflammatory Bowel Disease; IBDQ-R = Inflammatory Bowel Disease Questionnaire - Revised.

\section{Characterization of QoL}

An analysis of each of the items showed that those with higher mean scores, which corresponded to worst function, were item 11 "Fear of not finding a washroom" $(M=4.10$; $S D \pm 1.80$ ), item 19 - "Worries and anxieties related to the illness" $(M=3.90 ; S D \pm 1.60)$, and item 20 - "Troubled by a feeling of abdominal bloating" $(M=3.90 ; S D \pm 1.40)$. At the opposite extreme, corresponding to best function, were item 22 - "Rectal bleeding with bowel movements" $(M=1.90 ; S D \pm 1.10)$, item 28 - "Limited sexual activity" $(M=2.00 ; S D$ $\pm 1.10)$, and item 26 - "Accidental soiling of underpants" $(M=2.20 ; S D \pm 1.40)$. Item 21 "Feel relaxed and free of tension" $(M=4.00 ; S D$ \pm 1.10 ) was the only item in which none of the patients reported the worst function possible, with the minimum score of 2 and one of the highest mean scores, bearing in mind that this question was one of the reversed questions.

On average, the participants scored higher in the Systemic symptoms dimension, followed by the Emotional function and Bowel symptoms dimensions, which reflects worse QoL. The sample showed a better QoL in the Social function dimension.

The mean of the QoL dimensions ranged from 40 to 60 , which reflects a reasonable mean QoL. Overall, the mean score obtained in the IBDQ-R was 45.80 out of 100 points, with a minimum of 44.00 and a maximum of 72.30 points.

No statistically significant associations were found between the sociodemographic characteristics and the QoL of people with IBD to confirm that age, gender, marital status, and profession influence the QoL of patients with IBD. A statistically significant association was found between the education level and the So- cial function dimension, with the QoL in this context being higher in people with a higher education level.

With regard to the association between the behavioral habits (smoking and alcohol) and the QoL of people with IBD, a statistically significant difference was found in the Social function dimension and the total score, being that those individuals who smoked or had already smoked had a better QoL in the Social function dimension. No statistically significant difference was found in none of the dimensions in relation to drinking habits.

With regard to the association between the clinical variables and the QoL of patients with IBD, no statistical evidence was found to confirm that the type of disease (CD or UC) or the years of diagnosis influence the QoL of patients with IBD.

The comparison between the QoL of patients who had been hospitalized and those who had not been hospitalized showed that those who had been hospitalized had a better QoL in the Social function dimension, without statistically significant differences in the other dimensions or the total scale.

\section{Discussion}

In this study, there was a predominance of a young population with IBD, which is in line with the data obtained in the studies of several authors, namely those conducted by Silva (2015), Magalhães et al. (2015), Trindade et al. (2016), and Saurabh and Ahuja (2017), who reported a sample of people aged between 20 and 40 years, with most of them being older than 30 years, that is, young and active people who were affected by a significant loss of 
functional capacity and autonomy.

With regard to gender, the sample was composed of the same number of men and women, which is not in line with the majority of other authors, such as Trindade et al. (2016), with a sample of 200 patients with IBD where most of them were women, and Souza, Barbosa, Espinosa, and Belasco (2011), where there was a predominance of women (62.00\%).

As regards the family relationships, most of the participants in this study are married (65.80\%), which is in line with the study by Souza et al. (2011), with a mean of $69.90 \%$ of married participants, but in disagreement with the results obtained by Neubauer, Arlukiewicz, and Paradowski (2009), who found that most of the patients with CD live alone and do not start a family.

As for the education level, most of the participants in this study had completed the $12^{\text {th }}$ grade $(28.90 \%)$ and higher education $(28.90 \%)$, which is not in line with the results obtained by Coelho (2010), who found a higher percentage of participants with the $9^{\text {th }}$ grade $(56.90 \%)$. In some studies, the education level proved to be important as the higher the education level, the better the QoL of people with IBD (Coelho, 2010).

According to Magalhães et al. (2015), the difficulties experienced by people with IBD have an economic and social impact since $20 \%$ of the participants receive an a disability pension and $10-25 \%$ of them will face unemployment. In a total of 293 participants with IBD, Ramos et al. (2015) found that 214 were employed, 12 were receiving a disability pension, 16 were unemployed, 11 were in the process of losing their job due to repeated absences, 30 were homemakers, and 10 were students.

The analysis of the results of these studies shows that people with IBD are very likely to suffer changes in their professional life due to an exacerbation of symptoms, which can lead to absenteeism, hospitalization, or, at a more complicated phase, interruption of the professional activity. In this study, 16 of the 38 participants are unemployed (students, unemployed, and retired), being that the difference in relation to the number of employees is not significant (six participants).

Although tobacco consumption has been considered as one of the most important environ- mental factors in the pathogenesis of IBD, little is still known about the molecular and cellular mechanisms triggered in the intestine, which may lead to the development of CD or the prevention of UC (Pereira, 2014). In this study, the majority of participants reported never having smoked (65.80\%) and not drinking alcohol $(71.10 \%)$, which is in line with the studies by Coelho (2010) and Souza et al. (2011) with 54 smokers $(93.10 \%)$ versus four non-smokers $(6.90 \%)$ and 51 smokers $(49.50 \%)$ versus 52 participants non-smokers $(50.50 \%)$, respectively, with no significant difference between them. With regard to the most prevalent type of IBD, the most common type in this study was CD $(50.00 \%)$, followed by UC (26.30\%) and undetermined IBD (23.70\%), which is in line with several studies, namely those by Ramos et al. (2015) and Magalhães et al. (2015) which had a higher number of people with CD. However, Souza et al. (2011) found that most participants had UC.

IBD often requires hospitalization as a result of its various complications. In this study, 15 people $(39.50 \%)$ were hospitalized due to several complications, namely hemorrhage $(n=$ $4)$, exacerbation of the disease $(n=3)$, and stenosis/surgery $(n=2)$. Each of the remaining six participants had one of these complications: perianal abscess; initial phase of the disease; diarrhea; bowel inflammation; bowel perforation; and medication side effects. In the study by Coelho (2010), six people had undergone bowel surgery, five had CD (16.10\%), one had UC $(3.70 \%)$, and five people who had CD were hospitalized (8.62\%). According to Magalhães et al. (2015), 27 of the 85 participants had $\mathrm{CD}$ and had undergone surgery (31.80\%), seven patients had a history of perianal disease $(8.20 \%)$, and 47 patients $(55.30 \%)$ had already been hospitalized due to IBD ( 40 with CD and seven with UC).

In what concerns the association between the type of disease (CD or UC) and the years of diagnosis and the QoL of people with IBD, no statistically significant differences were found, which is in line with findings from Cohen, Bin, and Fayh (2010) that the QoL of people with IBD is not associated with the presence or not of CD or UC, provided that they are in phase of remission as disease activity is an important factor influencing QoL. 
Neubauer et al. (2009) found that the most important factor influencing QoL was disease activity, regardless of disease duration, in people with less than 5 years of diagnosis, whereas the length of hospital stay was the most important factor influencing QoL in those people who had been diagnosed 5 to 9 years before.

According to Dür et al. (2014), in their study on factors determining the well-being and QoL of people with $\mathrm{CD}$, the time of diagnosis was higher in women, although they were younger than men and had lower QoL levels.

In this study, people who had been hospitalized had better QoL in terms of the Social function dimension than those who had not been hospitalized, without statistically significant differences in the other dimensions or the total scale. It is known that approximately two-thirds of the people with CD develop complications that require several hospitalizations and surgeries (Magalhães et al., 2015). Thus, the imminent risk of psychological changes is understandable, with consequent reduction of QoL levels.

The levels of QoL in patients with IBD in remission are different from those of healthy people, being that all domains of QoL (physical, psychological, social, and environmental) are negatively associated with IBD symptoms, with a direct impact on the psychological well-being and the QoL of people with IBD, demonstrating a higher incidence during the active phase of the disease than during remission (Trindade et al., 2016).

In this study, the mean of all QoL dimensions is below $50.00 \%$ (between 40 and 60\%), which reflects a reasonable mean QoL.

On average, the Systemic symptoms (49.50\%), Emotional function (48.40\%), and Bowel symptoms (45.60\%) dimensions have higher scores, which reflects a worse QoL. The sample showed a better QoL in the Social function dimension (36.50\%). The results obtained in this study are in line with those obtained by Coelho (2010) who used the same instrument, but with reformulated questions and reversed scoring. This author found that the participants scored lower in terms of QoL in the Systemic symptoms dimension and higher in the Emotional function dimension.

Using the same instrument (IBDQ-R), Alowais, Alferayan, and Aljehani (2016) found that the participants reported a low level of QoL, with the Social function and Systemic symptoms dimensions having more impact than the Emotional function and Bowel symptoms dimensions, which is not in line with the present study. Cohen et al. (2010) found that the QoL was more affected by the Emotional function and Systemic symptoms dimensions, which is in agreement with the literature and this study, confirming the negative impact of the emotional and systemic aspects on the QoL of these patients. It can be concluded that the disease in its active phase has a negative influence in every dimension of the QoL of these patients, with a strong impact on their ability to perform their activities of daily living, independently and without limitations, in so far as it is characterized by frequent hospitalizations and prolonged treatments (Cohen et al., 2010; Magalhães et al., 2015).

These patients' concerns focus on their weakness, their difficulty in performing their activities of daily living, and their fear of the prognosis and the future (Trindade et al., 2016). The fear of developing cancer is a constant concern for patients/families with IBD, thus surveillance and screening programs should be implemented to make an early diagnosis. The topic of the QoL of people with IBD is relevant and challenging and should be further developed in order to obtain results that can be used for its improvement. This study had some limitations, mainly related to the difficulty in obtaining the sample and, consequently, the representativeness of the sample.

\section{Conclusion}

The purpose of this study was to identify the levels of QoL of patients with IBD.

The results of this study indicate that these patients have a reasonable QoL $(45.80 \%)$, which was a surprise to the extent that there is knowledge about the impact of this disease on how people experience life in its different dimensions, and that the symptoms bring about changes in attitudes and behaviors, as well as in the physical, social, and emotional domains, particularly during periods of exacerbation.

More specifically, this study aimed to assess some factors associated with the levels of QoL. None of the hypotheses was validated in full to the extent 
that statistically significant associations were only found between QoL and hospitalization, smoking habits, and education level.

This work has contributed to understanding the health status of the patients with IBD who attended the outpatient consultation of a district hospital and, consequently, devise intervention strategies to meet their needs and resolve identified problems. These strategies include the creation and implementation of a specific nursing consultation for IBD patients, which is already at a stage of project submission and waiting approval from the board of directors of the hospital. Therefore, the development of this study is important, especially in what concerns the planning of the nursing activities and the development of strategies for the delivery of individualized, comprehensive, holistic care that can promote an effective recovery process and the acceptance of the condition of chronic patient, with a view to empowering the patient, improving care delivery, and obtaining health gains.

\section{References}

Alowais, F. A., Alferayan, Y. A., \& Aljehani, R. M. (2016). Inflammatory Bowel Disease and Quality of Life in King Abdulaziz Medical City. Open Journal of Gastroenterology, 6,11-16. doi:10.4236/ojgas.2016.61003

Coelho, I. D. (2010). Qualidade de Vida e Doença Inflamatória Intestinal, avaliação de um grupo de doentes na consulta de doença inflamatória intestinal do Centro Hospitalar Cova da Beira (published Master's dissertation). Universidade da Beira Interior, Covilhã. Retrieved from file://C:/Users/user/Downloads/ isabeldiascoelhopdf\%20(9).pdf.

Cohen, D., Bin, C. M., \& Fayh, A. P. (2010). Assessment of quality of life of patients with Inflammatory Bowel Disease Residing in Southern Brazil. Arquivos de Gastroenterologia, 47(3), 285-289. doi:10.1590/ S0004-2803.201900000-43.

Dür, M., Sadlonova, M., Haider, S., Binder, A., Stoffer, M., Coenen, ... Stamm, T. A. (2014). Health determining concepts important to people with Crohn's disease and their coverage by patient-reported outcomes of health and wellbeing. Journal of Crohn's and Colitis, 8(1), 45-55. doi:10.1016/j. crohns.2012.12.014

Magalhães, J., Castro, F. D., Carvalho, P. B., Machado, J. F., Leite, S., Moreira., \& Cotter, J. (2015). Disability in Inflammatory Bowel Disease: Translation to Portuguese and Validation of the "Inflammatory Bowel Disease --- Disability Score”. GE Portuguese Journal of Gastroenterology, 22, 4-14. doi:10.1016/j. jpge.2014.10.002

Matos, L., \& Figueiredo, N. P. (2013). Gastrenterologia fundamental. Lidel: Lousã.

Neubauer, K., Arlukiewicz, A., \& Paradowski, L. (2009). Quality of Life in Inflammatory Bowel Disease. Advances in Clinical and Experimental Medicine, 18(1), 79-83. Retrieved from http://www.advances.umed. wroc.pl/pdf/2009/18/1/79.pdf

Neves, S. L. (2015). Experiência de crise na doença inflamatória intestinal: um estudo fenomenológico-existencial. (published Master's dissertation). Instituto Universitário Ciências Psicológicas, Sociais e da Vida. Lisboa. Retrieved from http://repositorio.ispa.pt/ bitstream/10400.12/3968/1/18274.pdf.

Pereira, P., M., C. (2014). O tabaco e a doença inflamatória intestinal. (published Master's dissertation). Universidade do Porto, Faculdade de Medicina. Retrieved from file://C:/Users/user/Desktop/mestrado/ DII\%20e\%20o\%20TABACO\%202014.pdf.

Ramos, A., Calvet, X., Sicilia, B., Vergara, M., Figuerola, A., Motos, J., ... Gomollo, F. (2015). IBD-related work disability in the community: Prevalence, severity and predictive factors. A cross-sectional study. United European Gastroenterology Journal, 3(4), 335-342. Retrieved from https://www. ncbi.nlm.nih.gov/pmc/articles/PMC4528207/ pdf/10.1177_2050640615577532.pdf

Rede Nacional de Especialidade Hospitalar e de Referenciação (2016). Gastrenterologia e Hepatologia. Retrieved from https://www.sns.gov.pt/wp-content/ uploads/2016/11/RRH-Gasteroenterologia_hepatologia.pdf.

Saurabh, K., \& Ahuja, V. (2017). Epidemiology of Inflammatory Bowel Disease in India: The Great Shift East. Inflammatory Intestinal Diseases, 2(2), 102-115. doi: 10.1159/000465522.

Silva, I. C. L. (2015). Qualidade de vida relacionada à saúde em pacientes acometidos por doença inflamatória intestinal tratados com terapia biológica. (Master's dissertation). Universidade Estadual Paulista. Retrieved from https://repositorio.unesp.br/bitstream/ handle/11449/128144/000849094.pdf?sequence

Smeltzer, C. S., Bare, G. B., Hinkle, L. J., \& Cheever, H. K. (2011). Bruner \& Suddarth. Tratado de Enfermagem Médico-cirúrgica. 12(1). Rio de Janeiro, Brasil: Editora Guanabara Koogan.

Souza, M. S., Barbosa, D. A., Espinosa, M. M., \& Belasco, A. G. S. (2011). Qualidade de vida de pacientes portadores de doença inflamatória intestinal. Acta Paulista 
de Enfermagem, 4(4), 479-484. doi: org/10.1590/ S0103-21002011000400006.

Trindade, I. A., Ferreira, C., \& Gouveia, J. P. (2016). Inflammatory bowel disease: The harmful mechanism of experiential avoidance for patients' quality of life. Journal of Health Psychology, 21(12), 2882-2892. doi:10.1177/1359105315587142

Vasconcelos, R.S., Rocha, M. A., Sousa, V. R. S., \& Amaral, V. R. S. (2018). Qualidade de vida de pacientes com doença inflamatória intestinal: revisão integrativa. ESTIMA, Brazilian Journal of Enterostomal Therapy, 16, e2118. doi: 10.30886/estima. v16.480_PT
Veríssimo, R. (2008). Quality of Life in Inflammatory Bowel Disease: Psychometric Evaluation of an IBDQ Cross-Culturally Adapted Version. Journal of Gastrointestinal and Liver Disease, 17(4), 439-444. Retrieved from https://www.ncbi.nlm.nih.gov/ pubmed/19104706

World Gastroenterology Organisation Practice Guidelines. (2015). Doença inflamatória intestinal. WGO Practice Guidelines DII. Retrieved from http://www. worldgastroenterology.org/UserFiles/file/guidelines/ inflammatory-bowel-disease-portuguese-2015.pdf. 
